\title{
Analysis of Microbial Contamination and Antibacterial Effect Associated with Toothbrushes
}

\author{
Ji-Hyang Kim, Da-Ae Kim, Hee-Soo Kim, Ji-Yeon Baik, So-Hee Ju, and Seol-Hee Kim ${ }^{\dagger}$ \\ Department of Dental Hygiene, College of Medical Science, Konyang University, Daejeon 35365, Korea
}

\begin{abstract}
The purpose of this study was to propose a method for the effective management of toothbrush contamination. Toothbrush microbial contamination was analyzed according to the duration of toothbrush use, frequency of toothbrush use per day, and toothbrush storage location. We also analyzed the microbial reduction effect of vinegar, antimicrobial mouth rinse, bamboo salt, and baking soda, which are sterilization materials that can be easily used every day. We collected 45 toothbrushes from university dormitories from May to June 2018. To determine the degree of microbiological contamination with general bacteria, coliform bacteria, and Staphylococcus aureus, bristle samples were cultured at $36^{\circ} \mathrm{C}$ for 24 hours using $3 \mathrm{M}^{\mathrm{T} \mathrm{M}}$ Petrifilm plates and then measured based on Petrifilm evaluation criteria. Toothbrush microorganisms were analyzed according to the duration of use, frequency of use per day, storage location, and effect of each sterilization material. General bacteria, coliforms, and $S$. aureus contamination increased with frequency and duration of use $(p<0.05)$. In particular, $S$. aureus showed a statistically significant increase to 36.15 $\mathrm{CFU} / \mathrm{ml}$ after 1 month, $504.23 \mathrm{CFU} / \mathrm{ml}$ after 2 months, and 2,386.67 CFU/ml after 3 months $(\mathrm{p}<0.05)$. We found that $1 \%$ vinegar was the most effective substance for reducing general bacteria, coliforms, and $S$. aureus. In addition, $1 \%$ antimicrobial mouth rinse solution applied for 5 minutes was the most effective in reducing $S$. aureus. It is crucial to recognize the importance of toothbrush care and store toothbrushes in a dry place and replace them periodically. We recommend use of vinegar and antimicrobial mouth rinse solution to disinfect toothbrushes. These should be applied as a $1 \%$ solution for at least 1 minute. Proper care of toothbrushes is important in maintaining oral health as well as overall health. Instructions on toothbrush care should be given when teaching children or adults how to brush teeth.
\end{abstract}

Key Words: Contamination, Microorganisms, Oral hygiene, Sterilization, Toothbrushing

\section{Introduction}

The oral cavity contains more than 700 types of bacteria and has the ideal temperature and humidity level for bacterial growth. It is, therefore, necessary to periodically remove bacteria from the teeth or tongue in the mouth, and one of the most common and effective methods for this is tooth brushing ${ }^{1)}$. Although a toothbrush is the most common oral hygiene care tool and is effectively utilized to prevent oral diseases by removing dental plaque in the oral cavity $^{2)}$, it can become easily contaminated with microorganisms, blood, saliva, and oral tissue shed in the oral cavity ${ }^{3)}$. Moreover, toothbrushes are often stored in an environment where bacteria, fungi, or yeast are present.
Toothbrushes are likely to be stored in the bathroom, where they can be contaminated by aerosols created during toilet cleaning ${ }^{4}$. Bathrooms often harbor species such as Streptococcus mutans, Lactobacillus, and Candida albicans $^{5}$, which have been found in the oral cavity. Potentially pathogenic bacteria, such as Staphylococcus aureus, Escherichia coli, and Pseudomonas, and viruses such as herpes simplex virus can also be found on toothbrushes. Nonetheless, there is a lack of awareness among the general public about toothbrush contamination, and most people do not recognize how important it is to store their toothbrush properly. As a result, toothbrushes are usually stored in an environment in which they can easily become contaminated by microorganisms. 
If a toothbrush is used for a long time without sterilization, it serves as a reservoir for pathogenic bacteria. If a contaminated toothbrush is used repeatedly inside the oral cavity, it can cause oral and even systemic infection $^{6}$. Pathological microorganisms on the toothbrush cause dental caries, gingivitis, and stomatitis ${ }^{7)}$. Elderly people with a weakened immune system who are exposed to $S$. aureus "superbug" strains can develop sepsis and enteritis. Importantly, $S$. aureus generates exotoxins known as enterotoxins, which cause food poisoning, resulting in symptoms of nausea, vomiting, abdominal pain, and diarrhea ${ }^{8-10)}$. It is, therefore, necessary to investigate the level of contamination of toothbrushes with not only general bacteria but also a variety of microorganisms that can potentially affect overall health, to develop proper toothbrush care methods.

Previous studies have examined various toothbrush sterilization methods such as hot air drying, hot water treatment, ozone treatment, ultraviolet (UV) treatment, and the use of sterilizing materials. Microwaves have been shown to be $98 \%$ effective in sterilizing toothbrushes. One study showed that on average, no colonies, or only one or two colonies, were observed after 1 minute of microwave sterilization after 24 hours of drying ${ }^{10)}$. UV sterilization showed more than $80 \%$ sterilization after 15 minutes of UV treatment ${ }^{11)}$. Nevertheless, these methods do not make much sense in terms of price or materials. It is not easy to use these techniques, and purchase of a toothbrush sterilizer is required. Thus, sterilization materials that are easily accessible are needed, as is education about how to easily avoid contaminated toothbrushes.

Among other materials used in daily life, baking soda is widely used to clean kitchenware and the home environment. Baking soda is recognized to be safe as it is used in toothpaste. It has been shown that baking soda has a good antibacterial effect, and its effectiveness is improved when used together with various other sterilization materials ${ }^{12)}$. Bamboo salt is used frequently in homes in Korea, and it has been used in folk medicine to alleviate periodontal disease, toothache, and bad breath. Bamboo salt is effective in suppressing the growth of microorganisms and in sterilization ${ }^{13)}$. The antibacterial effects of vinegar have been scientifically proven; these effects are related to the phenols in vinegar. It has been reported that vinegar with higher phenol content has a larger antibacterial effect ${ }^{14)}$. Antibacterial mouth rinse, which is used as an adjunct oral care tool, has the effect of disrupting formation of bacterial biofilm owing to its antimicrobial components. Antibacterial mouth rinse has shown bacteriostatic activity against most microorganisms in the oral cavity ${ }^{15)}$. All these materials are normally available in homes. Therefore, use of these materials would serve to reduce toothbrush contamination and health risks arising from microorganisms present on contaminated toothbrushes.

In this regard, we aimed to examine microbial contamination on toothbrushes according to the duration of toothbrush use, frequency of use per day, and toothbrush storage location, and to analyze the effect of sterilization materials that are easily accessible (vinegar, mouth rinse, bamboo salt, and baking soda) on reducing microorganisms. Our findings will be useful in suggesting effective ways to avoid toothbrush contamination that can be easily used by the general public.

\section{Materials and Methods}

\section{Participants}

This study obtained review exemption approval from the Institutional Review Board (IRB) of Konyang University (KYU-2018-034-01). A notice was drawn up and posted in university dormitory elevators from May to June 2018, stating the purpose of this study, i.e., to assess toothbrush microbial contamination and examine the antibacterial effects of various household materials. Forty-five toothbrushes in total were collected: 15 each by number of months in use. Each collected toothbrush was stored in a sterile container labeled with an identification number, its duration of use, frequency of daily use, and storage location.

\section{Methods}

Wearing sterile gloves, we extracted 25 to 30 bristles ( 1 batch) from each of the 45 collected toothbrushes using sterile tweezers and placed these into sterile trays for Experiments 1 and 2 .

In Experiment 1, to determine microbial contamination 
levels of the collected toothbrushes, we placed each bristle batch extracted from each of the 45 toothbrushes into a 15 $\mathrm{ml}$ conical tube containing $5 \mathrm{ml}$ distilled water, and centrifuged it, to separate the microorganisms from the bristles. After centrifugation, the distilled water in each tube was mixed, and $1 \mathrm{ml}$ was applied to $3 \mathrm{M}$ Petrifilm plates (3M-Korea, Seoul, Korea), as follows: 3M Petrifilm Aerobic Count Plates (AC) for general bacteria, 3M Petrifilm Staph Express Count Plates (STX) for S. aureus, and 3M Petrifilm Coliform Count Plates (CC) for coliform bacteria. These were cultured in an incubator (Huko, Seoul, Korea) at $36^{\circ} \mathrm{C}$ for 24 hours, and bacterial colonies were assessed according to Petrifilm evaluation criteria.

Experiment 2 was conducted together with Experiment 1. We randomly selected 10 toothbrushes, and prepared a $1 \%$ solution of each of the four materials (baking soda, vinegar, mouth rinse, and bamboo salt). Each solution was placed in a $5 \mathrm{ml}$ conical tube and applied to the toothbrush bristle for 1 minute and 5 minutes. At each time point, 1 $\mathrm{ml}$ of each solution was applied to AC, STX, and CC Petrifilm plates. After culture in an incubator at $36^{\circ} \mathrm{C}$ for 24 hours, bacterial colonies were evaluated according to Petrifilm criteria.

\section{Analytical methods}

The collected data were analyzed using PASW Statistics (ver. 18.0; IBM Co., Armonk, NY, USA). To assess microbial contamination levels of the 45 collected toothbrushes, we obtained a total of 135 data points for general bacteria, S. aureus, and coliform bacteria. Microbial contamination according to duration of toothbrush use, frequency of toothbrush use per day, and storage location was analyzed using t-tests and ANOVA. For analysis of the microorganism reduction effect according to application time ( 1 or 5 minutes) of each sterilization material, plates were examined at each time point for general bacteria, S. aureus, and coliform bacteria, with 240 data points in total. The p-value was set at 0.05 as the cutoff for statistical significance.

\section{Results}

\section{Microbial contamination according to duration of toothbrush use}

We assessed microbial contamination according to duration of toothbrush use. We found that general bacteria were observed on $86.7 \%$ of toothbrushes used for 1 month and $100 \%$ of those used for 3 months ( $p>0.05$ ). Coliform bacteria were observed on $73.3 \%$ of toothbrushes used for 1 month and 2 months and on $86.6 \%$ of those used for 3 months ( $\mathrm{p}<0.05)$. S. aureus was observed on $46.7 \%$ of toothbrushes used for 1 month and $86.7 \%$ of those used for 3 months $(\mathrm{p}>0.05)$.

Assessment of the degree of contamination by microorganisms, according to duration of toothbrush use, revealed that general bacteria increased to $2,489.23$ $\mathrm{CFU} / \mathrm{ml}$ on toothbrushes used for 1 month and to $5,028.67$ $\mathrm{CFU} / \mathrm{ml}$ on those used for 3 months ( $\mathrm{p}>0.05$ ). Coliform bacteria increased to $201.54 \mathrm{CFU} / \mathrm{ml}$ on toothbrushes used for 1 month and to $874.00 \mathrm{CFU} / \mathrm{ml}$ on those used for 3

Table 1. Degree of Microbial Contamination according to Duration of Toothbrush Use

\begin{tabular}{|c|c|c|c|c|}
\hline & 1 month $(n=15)$ & 2 months $(\mathrm{n}=15)$ & 3 months $(\mathrm{n}=15)$ & p-value \\
\hline \multicolumn{5}{|c|}{ No. of contaminated toothbrushes } \\
\hline General bacteria & $13(86.7)$ & $14(93.3)$ & $15(100)$ & 0.343 \\
\hline Coliform bacteria & $11(73.3)$ & $11(73.3)$ & $13(86.7)$ & 0.020 \\
\hline S. aureus & $7(46.7)$ & $9(60.0)$ & $13(86.7)$ & 0.066 \\
\hline \multicolumn{5}{|c|}{ Microbial contamination $(\mathrm{CFU} / \mathrm{ml})$} \\
\hline General bacteria & $2,489.23 \pm 617.12$ & $5,096.54 \pm 7,166.96$ & $5,028.67 \pm 4,666.84$ & 0.311 \\
\hline Coliform bacteria & $201.54 \pm 720.65$ & $561.54 \pm 1,146.39$ & $874.00 \pm 1,507.88$ & 0.340 \\
\hline S. aureus & $36.15 \pm 79.97$ & $504.23 \pm 1,506.81$ & $2,386.67 \pm 3,878.36$ & 0.040 \\
\hline p-value & 0.000 & 0.018 & 0.012 & \\
\hline
\end{tabular}

Values are presented as $\mathrm{n}(\%)$ or mean \pm standard deviation.

S. aureus: Staphylococcus aureus. 
months (p>0.05). S. aureus increased to $36.15 \mathrm{CFU} / \mathrm{ml}$ on toothbrushes used for 1 month, to $504.23 \mathrm{CFU} / \mathrm{ml}$ on those used for 2 months, and to 2,386.67 CFU/ml on those used for 3 months $(\mathrm{p}<0.05)$. In summary, the degree of microbial contamination increased with the duration of use (Table 1).

We assessed the differences in microbial contamination according to duration of toothbrush use and found that microbial contamination on toothbrushes used for 1 and 2 months was highest, in the order of general bacteria, coliform bacteria, and S. aureus; contamination on toothbrushes used for 3 months was highest in the order of general bacteria, S. aureus, and coliform bacteria $(\mathrm{p}<$ 0.05; Table 1).

\section{Microbial contamination by frequency of toothbrush use per day}

An analysis of microbial contamination according to the frequency of toothbrush use per day revealed that toothbrushes used three times a day had more general bacteria and coliform bacteria than those used twice a day ( $p>0.05$ ). In particular, the amount of $S$. aureus was four times higher on toothbrushes used three times a day than on those used twice a day ( $<<0.05$; Table 2$)$.

\section{Microbial contamination according to toothbrush storage location}

Microbial contamination levels assessed according to toothbrush storage location revealed that toothbrushes stored in a humid environment had more general bacteria than those stored in a dry environment $(\mathrm{p}>0.05)$. In particular, the amounts of coliform bacteria and $S$. aureus were three times higher in a humid environment than in a dry environment ( $\mathrm{p}<0.05$; Table 3$)$.

\section{Microbial reduction effect according to application time of microbial sterilization materials}

General bacteria were reduced the most using $1 \%$ vinegar, from $7,889.00 \mathrm{CFU} / \mathrm{ml}$ to $1.00 \mathrm{CFU} / \mathrm{ml}$ after 1 minute and to $0 \mathrm{CFU} / \mathrm{ml}$ after 5 minutes $(\mathrm{p}<0.05)$; this was followed by antibacterial mouth rinse $(p<0.05)$. Coliform bacteria were reduced the most using $1 \%$ vinegar, from $1,980.00 \mathrm{CFU} / \mathrm{ml}$ to $0 \mathrm{CFU} / \mathrm{ml}$ at 1 and 3 minutes $(\mathrm{p}<0.05)$; this was followed by bamboo salt $(\mathrm{p}<$ 0.05). S. aureus was reduced the most using antibacterial mouth rinse, from $2,432.00 \mathrm{CFU} / \mathrm{ml}$ to $10.00 \mathrm{CFU} / \mathrm{ml}$ after 1 minute and to $0.40 \mathrm{CFU} / \mathrm{ml}$ after 5 minutes $(\mathrm{p}>$ $0.05)$; this was followed by $1 \%$ vinegar ( $<<0.05$; Table 4$)$.

When vinegar was applied for 1 minute to general bacteria, coliform bacteria, and $S$. aureus, all three microorganisms were greatly reduced, to the point where nearly no colonies were observed. When vinegar was applied for 5 minutes to general bacteria and coliform bacteria, a similar pattern in microorganism reduction was observed (Fig. 1).

\section{Discussion}

We conducted this study to analyze microbial contamination of toothbrushes and the effect of materials

Table 2. Microbial Contamination according to Frequency of Toothbrush Use per Day (CFU/ml)

\begin{tabular}{lccc}
\hline & Two times/day $(\mathrm{n}=37)$ & Three times/day $(\mathrm{n}=8)$ & $\mathrm{p}$-value \\
\hline General bacteria & $4,200.27 \pm 5,231.33$ & $4,679.38 \pm 3,539.55$ & 0.807 \\
Coliform bacteria & $452.70 \pm 1,148.28$ & $1,383.13 \pm 1,607.05$ & 0.060 \\
Staphylococcus aureus & $706.22 \pm 1,740.66$ & $2,814.38 \pm 4,919.59$ & 0.039 \\
\hline
\end{tabular}

Table 3. Microbial Contamination according to Toothbrush Storage Location (CFU/ml)

\begin{tabular}{lccc}
\hline & Humid environment $(\mathrm{n}=35)$ & Dry environment $(\mathrm{n}=10)$ & $\mathrm{p}$-value \\
\hline General bacteria & $4,301.29 \pm 5,197.44$ & $4,230.00 \pm 4,162.28$ & 0.968 \\
Coliform bacteria & $715.86 \pm 1,369.09$ & $276.00 \pm 846.89$ & 0.216 \\
Staphylococcus aureus & $1,379.43 \pm 2,938.75$ & $36.50 \pm 86.70$ & 0.011 \\
\hline
\end{tabular}


Table 4. Microbial Reduction Effect according to Application Time of Microbial Sterilization Materials (CFU/ml)

\begin{tabular}{|c|c|c|c|c|}
\hline & Baseline & 1 minute & 5 minutes & p-value \\
\hline General bacteria & $7,889.00 \pm 4,026.41$ & & & \\
\hline Mouth rinse & & $799.00 \pm 777.38$ & $254.00 \pm 363.08$ & 0.001 \\
\hline Bamboo salt & & $1,475.00 \pm 2,244.46$ & $2,148.00 \pm 2,959.43$ & 0.009 \\
\hline Baking soda & & $4,880.00 \pm 4,078.84$ & $6,242.00 \pm 5,097.72$ & 0.199 \\
\hline Vinegar & & $1.00 \pm 2.23$ & 0 & 0.001 \\
\hline Coliform bacteria & $1,980.00 \pm 1,833.57$ & & & \\
\hline Mouth rinse & & $13.20 \pm 29.51$ & $12.60 \pm 28.17$ & 0.028 \\
\hline Bamboo salt & & $0.60 \pm 1.34$ & $1.40 \pm 3.13$ & 0.027 \\
\hline Baking soda & & $1,847.00 \pm 2,437.42$ & $2,644.20 \pm 2,938.60$ & 0.816 \\
\hline Vinegar & & 0 & 0 & 0.027 \\
\hline Staphylococcus aureus & $2,432.00 \pm 5,076.73$ & & & \\
\hline Mouth rinse & & $10.00 \pm 22.36$ & $0.40 \pm 0.89$ & 0.365 \\
\hline Bamboo salt & & $1,484.20 \pm 3,307.04$ & $2,420.00 \pm 4,819.95$ & 0.270 \\
\hline Baking soda & & $180.00 \pm 375.16$ & $81.80 \pm 161.99$ & 0.365 \\
\hline Vinegar & & $0.60 \pm 1.34$ & $0.60 \pm 1.34$ & 0.365 \\
\hline
\end{tabular}
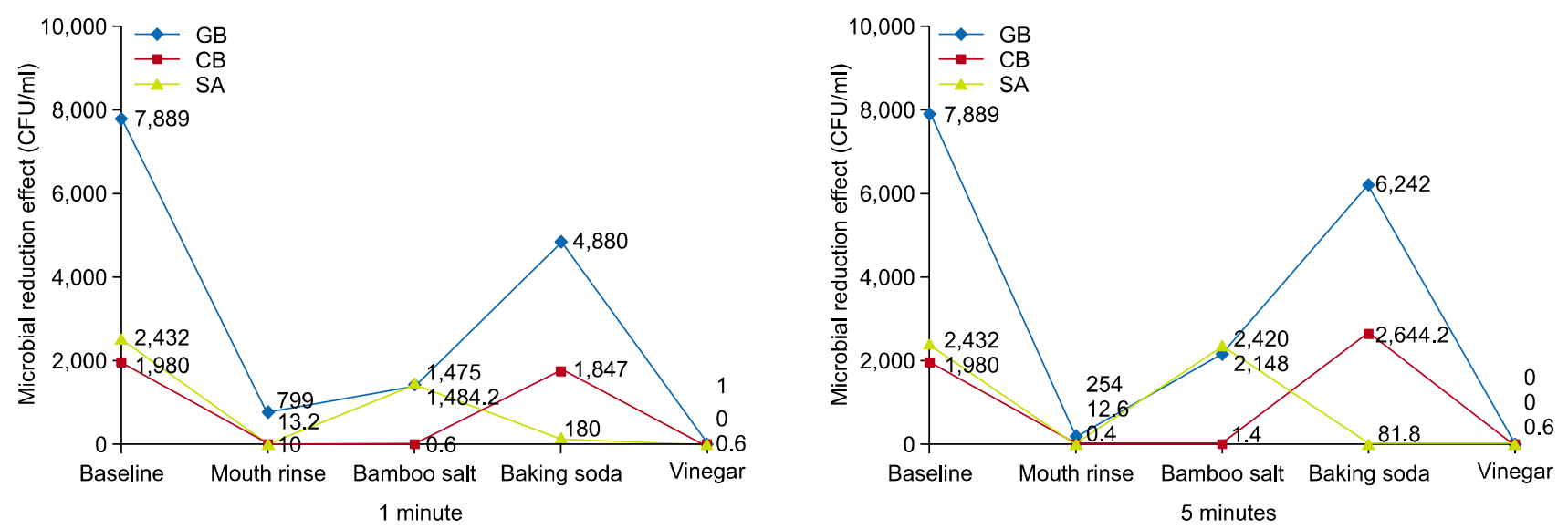

Fig. 1. Microbial reduction effect according to application time of microbial sterilization materials. GB: general bacteria, CB: coliform bacteria, SA: Staphylococcus aureus.

that are easily available on sterilizing toothbrushes, to identify problems in toothbrush care and suggest ways to efficiently care for toothbrushes.

To maintain good oral health, tooth brushing is performed every day to prevent dental caries and periodontal diseases and to remove food residue and dental plaque in the oral cavity. Most adults in Korea brush their teeth an average of 2.6 times per day ${ }^{16)}$. Toothbrushes consist of nylon synthetic resin bristles of varying thickness. This is the primary material used for bristles, as it absorbs less water and dries faster than natural bristles, to minimize bacterial growth ${ }^{17)}$. However, water flows down the toothbrush bristles and collects at the bottom of the bristles, where humidity is maintained, thereby creating an environment that is conducive to bacterial growth. If a toothbrush is not cleaned or is stored in a humid environment after tooth brushing, it gets contaminated by microorganisms from the oral cavity and bacteria in the air. Millions or even billions of microorganisms live on toothbrushes, which are returned to the mouth when people brush their teeth, and these can cause diseases such as food poisoning in people with a weakened immune system $^{18)}$. Some of the most common bacteria that cause food poisoning in Korea include $S$. aureus, Salmonella, and coliform bacteria. We examined microbial contamination of toothbrushes with general 
bacteria, which have identified in previous studies; we also examined toothbrush contamination with coliform bacteria and S. aureus, which have a high risk of leading to food poisoning. In addition, we also sought to assess microbial contamination according to duration of toothbrush use, frequency of use, and storage location.

Observation of microbial contamination according to duration of toothbrush use showed that after 3 months of use, general bacteria were found on $100 \%$ of toothbrushes, coliform bacteria on $73.3 \%$, and S. aureus on $86.7 \%$ ( $<<$ 0.05). Analysis of microbial contamination according to the frequency of toothbrush use per day found that general bacteria and coliform bacteria grew more often on toothbrushes used three times a day than on those used twice a day. In particular, microbial contamination with $S$. aureus was found to be four times higher on toothbrushes used three times a day than on those used twice a day. Frazelle and Munro ${ }^{5)}$ found that there was a significant correlation between repeated toothbrush use and bacteria found on the toothbrush, and that the oral cavity could be easily inoculated by a contaminated toothbrush. Osho et al. ${ }^{19)}$ reported that Staphylococcus were observed in $20 \%$ of toothbrushes used twice per day for 1 month or longer, and Pseudomonas aeruginosa was found on $40 \%$ of these. Raiyani et al. ${ }^{20)}$ observed S. mutans, Klebsiella, Candida, Pseudomonas, Lactobacillus, and E. coli on toothbrushes. Multidrug resistant bacteria, also referred to as superbugs, could cause infection in individuals who have developed resistance to antibiotics or in elderly people with a weakened immune system. Even though Staphylococcus exists as normal bacterial flora in the oral pharynx and nasal pharynx and it does not often cause infection owing to several resistance factors of the body, these microorganisms can cause infection of the soft tissue, salivary glands, dental extraction area, and alveolar bone. Therefore, education about the importance of proper toothbrush care is required ${ }^{21)}$.

In this study, microbial contamination by general bacteria and coliform bacteria was 2.5 to 4 times greater on toothbrushes used for 3 months than on those used for 1 month. Kim and $\mathrm{Kim}^{18)}$ also reported that the level of general bacteria on toothbrushes was found to be $6.7 \mathrm{log}$ $\mathrm{CFU} / \mathrm{ml}$, the highest recorded level of contamination.
Coliform bacteria, which are used as an indicator of oral hygiene, were detected in 41 of 75 toothbrushes (54.7\%), 13 of 29 toothbrush holders $(44.8 \%)$, and 29 of 65 cups used to store toothbrushes $(44.6 \%)$. These results demonstrate that the contamination of toothbrushes with coliforms was as high as that with general bacteria. Jo et al. $^{22)}$ detected coliform bacteria not only on toothbrushes but also in storage cups and toothbrush holders, suggesting that hygiene care of the implements used for storing toothbrushes is also important.

As for toothbrush storage location, general bacteria were found more often when toothbrushes were stored in a humid environment than in a dry environment. Importantly, microbial contamination with coliform bacteria and $S$. aureus was found to be three times higher in a humid than a dry environment. It is, therefore, important to reduce the risk of microbial contamination by storing toothbrushes in a clean place where they can dry easily; this is the generally recommended method. In particular, we found that $S$. aureus was increased to $36.15 \mathrm{CFU} / \mathrm{ml}$ on toothbrushes used for 1 month, to $504.23 \mathrm{CFU} / \mathrm{ml}$ on those used for 2 months, and to $2,386.67 \mathrm{CFU} / \mathrm{ml}$ on toothbrushes used for 3 months. It is therefore critical not only to care for but also to replace toothbrushes on a regular basis. The detection of coliform bacteria suggests a possible existence of pathological gastrointestinal microorganisms, such as Salmonella and Shigella ${ }^{23)}$. S. aureus is a Gram-positive bacterium that resides on the tongue or in saliva inside the oral cavity. S. aureus can cause opportunistic infection, leading to local or systemic infection. Notably, the presence of $S$. aureus in the oral cavity has been reported to cause endocarditis and infection of heart valve tissue owing to bacteremia, which highlights the importance of toothbrush care ${ }^{24)}$. Chung and Moon ${ }^{25)}$ examined the levels of bacteria on toothbrushes stored in lockers, in toothbrush cups, and in toothbrush sterilizers. Those authors reported a significantly lower level of bacteria on toothbrushes stored in sterilizers. Storing toothbrushes in a sterilizer, however, is impractical due to the cost of these sterilizers. In addition, a study on microorganisms and toxins that cause food poisoning and which are present on toothbrushes used by children in child care facilities reported that the level of microbial contamination of 
general bacteria in toothbrushes, which came in direct contact with the oral cavity, was staggering; thus, the risk of food poisoning was always present due to improper toothbrush care ${ }^{18)}$.

Whereas many methods to reduce bacteria on toothbrushes have been researched and published, almost none are actually used in practice. In this regard, we applied four materials that are easily accessible (antibacterial mouth rinse, vinegar, bamboo salt, and baking soda) at $1 \%$ for 1 minute and 5 minutes, to assess whether these had any antibacterial effect on general bacteria, coliform bacteria, and S. aureus. Vinegar and mouth rinse had a large effect on reducing general bacteria, vinegar and bamboo salt had a large effect on reducing coliform bacteria, and mouth rinse and vinegar had a large effect on reducing $S$. aureus $(\mathrm{p}<0.05)$. When $1 \%$ vinegar was applied to general bacteria, coliform bacteria, and $S$. aureus for 1 minute, the effect was so great that nearly no bacterial colonies were observed. Hence, immersing a toothbrush in $1 \%$ vinegar for more than 1 minute at home is expected to greatly contribute to improved toothbrush care.

Antibacterial mouth rinse is usually used to promote sterilization of the oral cavity. It has been reported that a $0.12 \%$ gluconate solution applied for 10 minutes has an efficient sterilization effect on toothbrushes and effectively removes C. albicans and Staphylococcus. As has been proven with UV sterilization, which showed an $86 \%$ reduction in microorganisms, the use of mouth rinse, a chemical sterilization method, is recommended for use without sterilizers ${ }^{26}$. In addition, chlorhexidine has a sterilizing effect against both Gram-positive and Gramnegative microorganisms. Soaking a toothbrush in chlorhexidine overnight has been found to be effective in preventing microbial contamination ${ }^{3)}$.

Vinegar showed an especially large antibacterial effect in this study, together with mouth rinse. Vinegar has been previously reported to have a substantial antibacterial effect. Kim et al. ${ }^{14)}$ reported that $1.5 \%$ or greater apple vinegar or black rice vinegar has a considerable sterilizating effect on S. mutans, and 4\% vinegar stopped growth of these bacteria. $\mathrm{Kim}$ and $\mathrm{Kim}^{27}$ found that vinegar suppresses the survival of pathogenic bacteria that cause food poisoning. It is therefore recommended to immerse a toothbrush in vinegar at home once per day; follow-up studies should be conducted in this respect.

The antibacterial effect of bamboo salt on $S$. mutans and Streptococcus sanguinis, which are both microorganisms present in the oral cavity, has been studied ${ }^{28)}$. Bamboo salt, which is sea salt roasted nine times at $800^{\circ} \mathrm{C}$ in bamboo canisters, has been used for detoxification in folk medicine and for treating ulcers or inflammation in the mouth by application to areas with pain or inflammation. Bamboo salt is a material that can be easily used and contains no toxic substances. Sodium bicarbonate, a component of baking soda, has been proven safe for use in the oral cavity and is used in some toothpastes. Sodium bicarbonate has been reported to be effective in reducing tooth plaque, gingivitis, tooth discoloration, and bad breath ${ }^{12)}$. In this study, we found it is effective in reducing bacteria and odor in toothbrushes; however, the antibacterial effect of sodium bicarbonate was lower than that of the other three materials tested.

Previous studies have analyzed the effect of 3\% hydrogen peroxide on a number of aerobic and anaerobic bacteria present on toothbrush bristles ${ }^{1)}$. Garlic and green tea have also been reported to be as effective as chlorhexidine. Such findings suggest that some herbal products may be used as toothbrush sterilization agents ${ }^{29)}$.

This study has several limitations. Caution should be used in generalizing the results as they were obtained using a small sample size. In addition, the oral cavity environment was not factored in. In further studies, a questionnaire survey should be used to collect information on additional factors that may influence the findings. Despite these limitations, the results of this study are important as we focused on not only microorganisms that affect the oral cavity but also those that can affect systemic health. We examined microbial contamination with general bacteria as well as coliform bacteria and S. aureus according to the duration of toothbrush use, frequency of daily use, and storage location. We present suggestions regarding how toothbrushes can be sterilized using materials that are easily available at home.

Tooth brushing is indispensable in tooth plaque care and serves as a basic method to prevent oral diseases. 
Education about appropriate tooth brushing methods is provided universally ${ }^{30)}$. The importance of toothbrush care, however, is not emphasized. If methods of toothbrush care were included in oral health education, this would help people to improve and maintain a healthy oral environment. The American Dental Association (ADA) recommends replacement of toothbrushes every 3 to 4 months because of worn-out bristles; however, the ADA makes no mention in its recommendation regarding toothbrush care that replacement can help avoid microbial contamination $^{7)}$. Educating people about toothbrush contamination and proper toothbrush care using sterilization methods will helps them to improve oral health behaviors and habits. Changing the perception of the general public regarding the importance of proper toothbrush care will greatly help in maintaining oral as well as overall health.

\section{References}

1. Beneduce C, Baxter KA, Bowman J, Haines M, Andreana S: Germicidal activity of antimicrobials and VIOlight ${ }^{\circledR}$ personal travel toothbrush sanitizer: an in vitro study. J Dent 38: 621-625, 2010. https://doi.org/10.1016/j.jdent.2009.08.011

2. Choi YK, Choi JS, Lim KO, Park DY, Kim YH: A study on the number of brushing strokes in toothbrushing education. $\mathrm{J}$ Dent Hyg Sci 18: 105-112, 2018. https://doi.org/10.17135/jdhs.2018.18.2.105

3. Naik R, Ahmed Mujib BR, Telagi N, Anil BS, Spoorthi BR: Contaminated tooth brushes-potential threat to oral and general health. J Family Med Prim Care 4: 444-448, 2016. https://doi.org/doi:10.4103/2249-4863.161350

4. Wetzel WE, Schaumburg C, Ansari F, Kroeger T, Sziegoleit A: Microbial contamination of toothbrushes with different principles of filament anchoring. J Am Dent Assoc 136: 758765, 2005. https://doi.org/10.14219/jada.archive.2005.0259

5. Frazelle MR, Munro CL: Toothbrush contamination: a review of the literature. Nurs Res Pract 2012: 1-6, 2012. https://doi.org/10.1155/2012/420630

6. Sato S, Ito IY, Lara EH, Panzeri H, Albuquerque Junior RF, Pedrazzi V: Bacterial survival rate on toothbrushes and their decontamination with antimicrobial solutions. J Appl Oral Sci 12: 99-103, 2004.
https://doi.org/10.1590/S1678-77572004000200003

7. Karibasappa GN, Nagesh L, Sujatha BK: Assessment of microbial contamination of toothbrush head: an in vitro study. Indian J Dent Res 22: 2-5, 2011.

https://doi.org/10.4103/0970-9290.79965

8. Park KH, Kim JY, Kim JB: Sterilizing effects of the ultraviolet ray toothbrush sterilizing devices. J Korean Acad Oral Health 26: 89-99, 2002.

9. Lee EH, Ko JY, Kim JS: Distribution and characteristics of heterotrophic plate count bacteria in water samples from drinking water dispensers. J Microbiol 44: 244-250, 2008.

10. Lee HS, Kang KH, Kim KM, et al.: Dental microbiology. Chonggumunhwasa Publishing, Seoul, pp.201-222, 2014.

11. Yang EJ, Lee MS, Kim JW: Studies on the improvement of UV sterilizer for toothbrush. J Nat Sci Pai Chai Univ 11: 41-44, 1998.

12. Kim NH, Mun SJ, Kim AH, et al.: The antimicrobial and anti-plaque effect of dentifrice containing baking soda and triclosan. J Korean Acad Oral Health 35: 10-17, 2011.

13. Oh HN, Hong SJ, Lee HJ, Choi CH: The effects of bamboo salt solution on remineralization of artificial caries-like lesions. J Korean Soc Dent Hyg 12: 335-343, 2012.

14. Kim OM, Ha DJ, Jeong YJ: Antibacterial activity of vinegars on streptococcus mutans caused dental caries. Korean J Food Preserv 10: 565-568, 2003.

15. Ankola AV, Hebbal M, Eshwar S. How clean is the toothbrush that cleans your tooth? Int J Dent Hyg 7: 237-240, 2009. https://doi.org/10.1111/j.1601-5037.2009.00384.x

16. Korea Centers for Disease Control and Prevention (KCDC): National nutrition survey report of national health statistics in Korea. KCDC Publishing, Seoul, p.134, 2016.

17. Han SM, Yang SM, Lee YM, et al.: The study on toothbrush filaments. J Periodontal Implant Sci 32: 857-864, 2002.

18. Kim JS, Kim JB: Prevalence and toxin genes of food-borne pathogens isolated from toothbrush in child care center. $\mathbf{J}$ Food Hyg Saf 30: 242-248, 2015. https://doi.org/10.13103/JFHS.2015.30.3.242

19. Osho A, Thomas BT, Akande YA, Udor RD. Toothbrushes as fomites. J Dent Oral Hyg 5: 92-94, 2013.

20. Raiyani CM, Arora R, Bhayya DP, Dogra S, Katageri AA, Singh V: Assessment of microbial contamination on twice a day used toothbrush head after 1-month and 3 months: an in vitro study. J Nat Sci Biol Med 6: 44-48, 2015. 
https://doi.org/10.4103/0976-9668.166072

21. Kim SH: Survey of staphylococcus epidermidis contamination on the hands of dental hygienists and equipment surface of dental clinics. J Dent Hyg Sci 17: 472-480, 2017.

https://doi.org/10.17135/jdhs.2017.17.6.472

22. Jo SH, Kim CI, Ha SD: Outbreak pattern forecasting of food-borne disease in group food services in Korea. J Food Hyg Saf 24: 19-26, 2009.

23. Yu OK, Kim HS, Buyn MS, Kim MN, Cha YS: A comparison study of hygiene status in meals for poorly-fed children through microbiological analysis. J Nutr Health 47: 214-220, 2014. https://doi.org/10.4163/jnh.2014.47.3.214

24. Lee SY, Kim JG, Baik BJ, et al.: Antimicrobial effect of essential oils on oral bacteria. J Korean Acad Pediatr Dent 36: 1-11, 2009.

25. Chung MS, Moon IK: Contamination of isolated microorganisms from the toothbrushes according to storage. $\mathrm{J}$ Korean Health Fundam Med Sci 9: 44-50, 2016.

26. Tomar P, Hongal S, Saxena V, Jain M, Rana K, Ganavadiya R: Evaluating sanitization of toothbrushes using ultra violet rays and $0.2 \%$ chlorhexidine solution: a comparative clinical study. J Basic Clin Pharm 6: 12-18, 2014.

27. Kim YM, Kim KH: Effects of vinegar and lactic acid on the survival of pathogens causing food poisoning of sliced raw fish meat. J Life Sci 12: 669-675, 2002.

28. Ryu EH, Lee SJ, Shin DK, Jung JH: Study on mineral concentration changes and anticariogenic effects of organic bamboo salt with different number of baking times J Agric Life Sci 52: 61-69, 2018.

https://doi.org/10.14397/jals.2018.52.1.61

29. Anand PJ, Athira S, Chandramohan S, Ranjith K, Raj VV, Manjula VD: Comparison of efficacy of herbal disinfectants with chlorhexidine mouthwash on decontamination of toothbrushes: an experimental trial. J Int Soc Prev Community Dent 6: 22-27, 2016. https://doi.org/10.4103/2231-0762.175406

30. Kim KE, Ahn ES, Han JH: Variation in the index of dental plaque removal and practice assessment after instruction on toothbrushing. J Dent Hyg Sci 15: 220-225, 2015. https://doi.org/10.17135/jdhs.2015.15.2.220 